\title{
The Disjunctive Conception of Perceiving
}

\author{
Adrian Haddock ${ }^{*}$ \\ Department of Philosophy, University of Stirling, UK
}

John McDowell's conception of perceptual knowledge commits him to the claim that if I perceive that $\mathrm{P}$ then $\mathrm{I}$ am in a position to know that I perceive that $\mathrm{P}$. In the first part of this essay, I present some reasons to be suspicious of this claim - reasons which derive from a general argument against 'luminosity' - and suggest that McDowell can reject this claim, whilst holding on to almost all of the rest of his conception of perceptual knowledge, by supplementing his existing disjunctive conception of experience with a new disjunctive conception of perceiving. In the second part of the essay, I present some reasons for thinking that one's justification, in cases of perceptual knowledge, consists not in the fact that one perceives that $P$ but in the fact that one perceives such-and-such. I end by suggesting that the disjunctive conception of perceiving should be understood as a disjunctive conception of perceiving such-and-such.

Keywords: McDowell; knowledge; perceiving; luminosity

1. There is a man in front of me chewing on the end of his pencil. How I do know this? Why, because I see a man in front of me chewing on the end of his pencil. That is to say, I take it that there is a man in front of me doing that, because my (visual) experience supplies me with a reason for taking it that this is so, in the shape of the fact that Isee a man in front of me doing that. This is a truly excellent reason, for if I see a man in front of me doing that then there is a man in front of me doing that. Consequently, because I take it that this is so for this reason, I do not merely take it that this is so, but know that this is so - I know that there is a man in front of me, chewing on the end of his pencil.

These are seemingly natural thoughts. But there is an argument - a variant on the Argument from Illusion ${ }^{1}$ - which purports to show that they must be rejected.

\footnotetext{
*Email: adrian.haddock@stir.ac.uk
} 
It is possible that I have an experience 'just like' the experience I have when I see a man in front of me chewing on the end of his pencil in a case in which there is no man in front of me chewing on the end of his pencil. In a case like this, I could not see a man in front of me doing that, because there would be no man in front of me doing that; at best, I could dream of a pencil-chewing man, or have a hallucination of such a man.

Here we have two possible cases: a 'good' case, and a 'bad' case. In the good case, I see a man in front of me chewing on the end of his pencil. And let us say that, in the bad case, I have a hallucination of a man in front of me doing that. The experience I have in the good case is 'just like' the experience I have in the bad case. According to this variant on the Argument from Illusion, it follows that the reasons which my experience supplies me with must be the same in the good case as they are in the bad case. The fact that I see a man in front of me chewing on the end of his pencil is not a reason which my experience can supply me with in the bad case, because in the bad case I do not see, but rather have a hallucination of, a man in front of me doing that. So, according to this variant on the Argument, this is not a reason which my experience can supply me with in the good case either. (Just so, the fact I have a hallucination of a man in front of me doing that is not a reason which my experience can supply me with in the good case, because in the good case I do not have a hallucination of, but rather see, a man in front of me doing that. So, according to this variant on the Argument, this is not a reason which my experience can supply me with in the bad case either.)

The only reasons which my experience can supply me with are those which are neutral between the good case and the bad case, e.g., my experience can only supply me with a reason consisting in the fact that I seem to see a man in front of me chewing on his pencil. So, we must abandon the seemingly natural thoughts with which we began.

In 1982, John McDowell gave a lecture which sought to rescue these seemingly natural thoughts from this variant on the Argument from Illusion (McDowell 1982). McDowell pointed out that it does not simply follow, from the fact that my experience in the good case is 'just like' my experience in the bad case, that the reasons which my experience supplies me with must be the same in both cases. Why not say instead that, even if my experience in the good case is 'just like' my experience in the bad case, it can still supply me with a reason which my experience in the bad case cannot supply me 
with, e.g., a reason consisting in the fact that I see a man in front of me chewing on his pencil?

Expressed differently, McDowell's suggestion is that my experience can either supply me with a reason consisting in the fact that I see such-and-such, or supply me with a reason consisting merely in the fact that I seem to see such-and-such. ${ }^{2}$ That McDowell originally expressed his suggestion in the guise of a disjunction is one reason why it has come to be known as the disjunctive conception of experience $(1982,386)$.

Since the time of McDowell's lecture, interest in the disjunctive conception has not merely grown but spiralled - if not quite out of control, at least in several different directions. One way to summarise McDowell's position would be to say that, even though my experience in the good case is 'just like' my experience in the bad case, there is a fundamental difference between my experiences, in terms of the reasons they can supply me with. The idea of a fundamental difference between experiences which are 'just like' one another is central to recent writings on the disjunctive conception. However, McDowell's concern with experience's capacity to supply me with reasons, and therefore with knowledge - which provided the central rationale for his conception is discarded by these recent writings, in favour of a quite different understanding of the idea of a fundamental difference between experiences which are 'just like' one another.

The thoughts with which these recent writings begin are harnessed by the moniker 'naïve realism', and maintain that, when I see, e.g., a man in front of me chewing on the end of his pencil, what I see partly constitutes my experience itself (so a man in front of me chewing on the end of his pencil partly constitutes my experience, in this case). ${ }^{3}$ Naïve realism is threatened by a different variant on the Argument from Illusion, according to which it follows from the fact that my experience in the good case is 'just like' my experience in the bad case that my experience must be constituted by the same things in each case. In the bad case, my experience cannot be constituted by what I see - i.e., by a man in front of me chewing on the end of his pencil - because in the bad case I do not see a man in front of me chewing on the end of his pencil. So, according to this variant on the Argument, my experience cannot be constituted by what I see in the good case either. The version of the disjunctive conception which figures in these recent writings insists that, on the contrary, my experience in the good case and my experience 
in the bad case are differently constituted, even though they are 'just like' one another: the former is constituted by what I see, even though the latter is not.

Expressed differently, and more generally, this version of the disjunctive conception insists that my experience is either constituted by what I see - e.g., by a man chewing on the end of his pencil - or constituted otherwise. Once again, there is a fundamental difference between the experiences; but the idea of this difference is no longer understood in terms of the different reasons which my experiences can supply me with. Because of its concern with the nature of experience, we might refer to this conception of experience as the metaphysical disjunctive conception; and because of its concern with experience as a source of reasons and knowledge we might refer to McDowell's conception of experience as the epistemological disjunctive conception. ${ }^{4}$

It is sometimes maintained that whatever constitutes one's experience constitutes, inter alia, the phenomenology of one's experience. To say that my experience in the good case is 'just like' my experience in the bad case seems to be to say that my experience has the same phenomenology in both cases. What exactly this means is hard to pin down. But one standard way to gloss it is to say that how things seem from my point of view is the same in the good case (when I see the man chewing away) as it is in the bad case (when I have a hallucination of him doing that). So, if whatever constitutes my experience constitutes its phenomenology, then in claiming that what constitutes my experience in the good case is different from what constitutes my experience in the bad case, the metaphysical version makes it look as if my experience in the good case must differ in phenomenology from my experience in the bad - as if how things seem from my point of view when I am in the good case cannot be the same as how things seem from my point of view when I am in the bad case. This might seem to be the beginning of a criticism of the metaphysical disjunctive conception. However, many of its proponents insist on this phenomenological difference. They insist that, in this sense, my experience in the good case is not 'just like' my experience in the bad case. ${ }^{5}$ But they claim that my good experience is 'just like' my bad experience in a different sense, i.e., in the sense that it is not possible to know by introspection alone which experience I am having: whether I am having an experience in which I see a man in front of me chewing away, as opposed to an experience in which I have a hallucination of such a man. How things seem from 
my point of view when I am in the good case is not the same as how things seem from my point of view when I am in the bad case. Nevertheless, introspection alone cannot tell me whether the case I am in is good rather than bad.

2. I have rehearsed (what I take to be) some reasonably familiar material centrally to emphasise the differences between McDowell's epistemologically inflected project and the project of those who endorse the metaphysical disjunctive conception.

It seems to be possible to endorse the seemingly natural thoughts which McDowell's disjunctive conception is designed to protect without taking a view as to the merits of 'naïve realism', whether the latter is advanced as a claim about the phenomenology of experience, or merely as a claim about what constitutes experience (assuming it is possible to keep claims about what constitutes experience apart from claims about what constitutes its phenomenology). But this essay is concerned neither with 'naïve realism', nor with the metaphysical disjunctive conception. Its concern is with features of McDowell's epistemological disjunctive conception which have not yet been brought into focus, but which must be central to any assessment of its merits. ${ }^{6}$

It is a truth to which philosophers often pay lip service that McDowell agrees with Wilfrid Sellars "that knowledge - at least as it is enjoyed by rational animals - is a certain sort of standing in the space of reasons" (McDowell 1995, 395) "of justifying and being able to justify what one says" (Sellars 1956, 288-9). But it ought to be stressed ${ }^{7}$ that at least part of the point of this Sellarsian doctrine is "to exclude an externalistic view of epistemic satisfactoriness, a view according to which one can be entitled to a belief without being in a position to know what entitles one to it" (McDowell 2008, 256). McDowell's central contention is that, if I enjoy perceptual knowledge that $\mathrm{P}$, then not only do I have a reason, or a justification, or an entitlement, or a warrant - he tends to use the notions of reason, justification, entitlement, and warrant interchangeably ${ }^{8}-$ to believe that $\mathrm{P}$, but this reason (or justification, or entitlement, or warrant) does not fall short of the fact known (i.e., the fact that P). And, in most if not all of his writings which deal with perceptual knowledge, he assumes that this reason consists in the fact that I perceive that P; e.g., in the case of specifically visual perceptual knowledge, in the fact that I see that $\mathrm{P} .{ }^{9}$ So far I have not made use of the idea of perceiving that $\mathrm{P}$ in my presentation of 
McDowell's disjunctive conception, preferring to employ the idea of perceiving suchand-such - e.g., the idea of seeing a man in front of me chewing on his pencil, rather than that of seeing that there is a man in front of me chewing on his pencil. My reasons for this policy will emerge in the sequel. But, staying with the idea of perceiving that $\mathrm{P}$, it is McDowell's thought that if I perceive that $\mathrm{P}$, then I am entitled to believe that $\mathrm{P}$, precisely by the fact that I perceive that P. As he puts it, "if one undergoes an experience on the "good" side of the disjunction [i.e., if one perceives that things are a certain way] that warrants one in believing - indeed presents one with an opportunity to know - that things are [this way]" (McDowell 2006a, 234); i.e., if one perceives that $P$ then one is warranted in believing that $\mathrm{P}$, and it is precisely that fact - the fact that one perceives that $\mathrm{P}$ - which warrants one so to believe. Putting this thought together with McDowell's anti-externalist, Sellarsian thought that if I am entitled to believe that P then I am in a position to know what entitles me to believe that $\mathrm{P}$, we arrive at the claim that, if I perceive that $\mathrm{P}$, then $\mathrm{I}$ am in a position to know that I perceive that $\mathrm{P} .{ }^{10}$

(McDowell (2003) writes as if he thinks that, if I perceive that P, then not only is there a reason for me to believe that $\mathrm{P}$ (a reason which consists in the fact that I perceive that $\mathrm{P}$ ), but $\mathrm{I}$ have a reason to believe that $\mathrm{P}$ (a reason which consists in the fact that $\mathrm{I}$ perceive that $\mathrm{P})$. It is plausible to suppose that McDowell considers himself entitled to speak in this way precisely by his endorsement of the claim at which we have just arrived, because it is plausible to think that I can have a fact as a reason to believe that $\mathrm{P}$ only if I am in a position to know this fact.)

For reasons which will become clear as we proceed, McDowell's claim that if I perceive that $\mathrm{P}$ then $\mathrm{I}$ am in a position to know that I perceive that $\mathrm{P}$ might be described as his 'luminosity' claim. After clarifying what McDowell's luminosity claim does, and does not, amount to - by means of a comparison between McDowell's epistemological writings and some recent work by Sebastian Rödl - I shall suggest that there are reasons for McDowell to abandon this claim, and, as a result, reasons for him to abandon one of the two thoughts which together entail this claim. The first of these thoughts (i.e., the Sellarsian thought that if I am entitled to believe that $\mathrm{P}$ then I am in a position to know what entitles me to believe that $\mathrm{P}$ ) is more fundamental to McDowell's overall epistemological project than the second thought (i.e., the thought that if I perceive that $\mathrm{P}$ 
then I am entitled to believe that $\mathrm{P}$ by the fact that I perceive that $\mathrm{P}$ ). So, I shall suggest that what McDowell should do is hold on to the first of these thoughts, by rejecting the second, and replacing it with a new disjunctive conception, a disjunctive conception of perceiving - effectively, a disjunctive conception of (what figures in McDowell's disjunctive conception of experience as) the good case. This will enable McDowell to avoid the luminosity claim, whilst retaining both the Sellarsian thought and his central contention that, if I enjoy perceptual knowledge that $\mathrm{P}$, then I have a reason to believe that $\mathrm{P}$ which does not fall short of the fact that $\mathrm{P}$.

However, this new conception will give rise to the question of whether it is possible to understand the reason integral to perceptual knowledge as consisting in the fact that I perceive such-and-such, rather than in the fact that I perceive that $P$. I shall suggest that this is indeed possible. That will take us to a new disjunctive conception of perceiving - a disjunctive conception of perceiving such-and-such, rather than a disjunctive conception of perceiving that $\mathrm{P}^{11}$ I shall suggest that McDowell has reason to endorse this disjunctive conception of perceiving such-and-such.

My aim, in this essay, is simply to work through the details of McDowell's epistemological project, with a view to showing not only that there is an aspect of his project he ought to abandon, but also how he can abandon it without unsettling his fundamental epistemological commitments. Because I share many of these commitments, the disjunctive conception of perceiving such-and-such at which we will eventually arrive is a conception which I think we all ought to endorse. But I cannot argue for this stronger claim here. In this essay, my aim must be much more limited: to argue that, in the light of the commitments which shape his broader epistemological project, there are reasons for McDowell to endorse this disjunctive conception.

3. Perceiving that $\mathrm{P}$ puts me in a position to know that $\mathrm{P}$; or, as $\mathrm{McD}$ Dowell sometimes puts it - for he uses these notions interchangeably too - it presents me with an opportunity to know that $\mathrm{P}$, or, it makes knowledge that $\mathrm{P}$ available to me. McDowell wants to allow for cases in which (e.g.) I see that P, but I do not know (visually) that $\mathrm{P}$ because I do not believe that P. He offers the following as an example of such a case (McDowell 2003): 
"I thought I was looking at your sweater under one of those lights that make it impossible to tell what colours things are, but I now realize I was actually seeing that it was brown.” In saying this, one registers that one had, at the relevant past time, an entitlement that one did not then realize one had. One was in a position to acquire a bit of knowledge about the world, but because of a misapprehension about the circumstances, one did not avail oneself of the opportunity. (158)

Perhaps a (normally) reliable friend has told me that the lights in the room we are in are of the sort which make it impossible to tell what colours things are, thereby making it reasonable for me both to refuse to believe that I am seeing that your sweater is brown, and - because vision is the only relevant source of information available to me - to refuse to believe that your sweater is brown; refusals I consequently effect, thereby ensuring that I do not know (visually) that your sweater is brown, even though, actually, I was seeing that your sweater is brown, and so had the opportunity to know this fact. And not just this fact: I also had the opportunity to know that I was seeing that your sweater is brown, but my misapprehension led me not to avail myself of this opportunity.

In order to avail myself of the opportunity to know that your sweater is brown an opportunity I have simply in virtue of seeing that your sweater is brown - it is not enough for me simply to believe that your sweater is brown; I need to believe that your sweater is brown because I see that it is brown, i.e., because of the very thing whose being the case puts me in a position to know that your sweater is brown. And this 'because' is the 'because' of the species of causal explanation which shows rationality to be in operation - as it would not be in operation if I were to believe that your sweater is brown in a case in which it is reasonable for me to refuse to believe that your sweater is brown. $^{12}$ (In such a case, I might believe that your sweater is brown because I see that it is brown; but this causal explanation would not show rationality to be in operation.)

According to recent work by Sebastian Rödl (2007), I exercise my fallible capacity to know things through perception only if I believe that $\mathrm{P}$ because I perceive that $\mathrm{P}$ - where the 'because' is the 'because' of the species of causal explanation which shows rationality to be in operation. In general, a fallible capacity is one whose "exercise is liable to be thwarted by unfavourable circumstances" (151). However, the exercise of my 
fallible capacity to know things is also liable to be thwarted if I am in what Rödl (following Andrea Kern (2006, 332-33)) calls "reflectively unfavourable circumstances" (154, n. 19) - circumstances which are not unfavourable, but which it is reasonable for me to believe are unfavourable. Circumstances in which the lights make it impossible to tell what colours things are by looking count as unfavourable; if I was in those circumstances then I could not see that your sweater is brown. By contrast, circumstances in which there is nothing wrong with the lighting, but which it is reasonable for me to take to be circumstances in which there is something wrong with the lighting, count as reflectively unfavourable; if I was in those circumstances, then even though I might see that your sweater is brown, I would - given adequate doxastic responsibility on my part, and given that vision is the only relevant information-source available - refuse to believe that your sweater is brown, and, consequently, neither believe that your sweater is brown because I see that your sweater is brown, nor exercise my capacity to get to know the colours of things through visual perception.

It is no accident that Rödl's work in epistemology is relevant at this juncture because its goal is (inter alia) "that of articulating the account of self-consciousness and spontaneous knowledge contained in McDowell's epistemological writings" (147, n. 11). The knowledge that I perceive that $\mathrm{P}$ which, according to McDowell, I am at least in a position to acquire whenever I perceive that $\mathrm{P}$ is, according to Rödl, spontaneous knowledge - in contrast to perceptual knowledge that $\mathrm{P}$, which is receptive knowledge. Rödl explains the difference between spontaneous and receptive knowledge by saying that whereas the latter (e.g., perceptual knowledge that P) is "a distinct reality from its object" (140) (in this case, the fact that P), the former (e.g., knowledge that I perceive that P) and its object (in this case, the fact that I perceive that P) are "the same reality" (145). He goes on to explain this second form by saying that "if someone bears a receptive nexus to an object by which she is in a position to gain [receptive] knowledge of it then she knows that she does, and knows it by bearing this nexus to the object" (1434). Perceiving that $P$ is one case of bearing a receptive nexus to an object (i.e., to the fact that $\mathrm{P}$ ) by which I am in a position to gain receptive (specifically, perceptual) knowledge of it. So, it seems that, according to Rödl, if I perceive that P, then I know that I perceive that P. That claim seems to be what Rödl has in mind when he says that my knowledge 
that I perceive that $\mathrm{P}$ is spontaneous, i.e., "the same reality" as its object. But this claim is surely too strong, for a reason we have seen - a reason which Rödl helped us to formulate: I might perceive that $\mathrm{P}$ but not know that I perceive that $\mathrm{P}$, precisely because I am in reflectively unfavourable circumstances.

McDowell's own explanation of knowledge of perceiving that $\mathrm{P}$ avoids this last claim, because it insists - contra Rödl - that, from the fact that "someone bears a receptive nexus to an object by which she is in a position to gain ... knowledge of it", it does not follow that "she knows that she does", merely that she has an opportunity to know that she does, an opportunity which she may not avail herself of thanks (e.g.) to her being in reflectively unfavourable circumstances. And in order to avail herself of this opportunity - an opportunity she enjoys simply in virtue of perceiving that $\mathrm{P}-$ it is, once again, not enough that she acquires the associated belief, the belief that she perceives that $\mathrm{P}$; she needs to acquire this belief because she perceives that $\mathrm{P}$, i.e., because of the very thing whose being the case puts her in a position to know that she perceives that $\mathrm{P}$ where this 'because' is, once again, the 'because' of that species of causal explanation which shows rationality to be in operation. ${ }^{13}$ This is not to deny that, unlike my perceptual knowledge that $\mathrm{P}$, my knowledge that I perceive that $\mathrm{P}$ is, for McDowell, in some sense spontaneous rather than receptive. The sense in question can be explained by saying that whereas the object of spontaneous knowledge (e.g., the fact that I perceive that $\mathrm{P}$ ) suffices to put me in a position to know itself (e.g., to know that I perceive that P), the object of receptive knowledge (e.g., the fact that your sweater is brown) does not suffice to put me in a position to know itself; to know the latter, I need to bear a receptive nexus to the object (e.g., I need to perceive that it is brown). That is not quite the sense Rödl had in mind when he said that spontaneous knowledge and its object are "the same reality". But is hard to see how they can be "the same reality", in this sense, by Rödl own lights, if I might, e.g., perceive that P but - thanks to the unfortunate fact that I am in reflectively unfavourable circumstances - fail to know that I perceive that $P$.

However, even though McDowell's explanation avoids the worry which Rödl's explanation gives rise to, it gives rise to a worry of its own; a worry which - I suggest can and should be avoided by embracing a disjunctive conception of perceiving. 
4. Consider the following guise of McDowell's luminosity claim: if one sees that $\mathrm{P}$, then one is in a position to know that one sees that $\mathrm{P}$. What worries might this claim inspire?

One worry is rather naïve. There might be circumstances in which one sees that $\mathrm{P}$ even though, were one to believe that $\mathrm{P}$, one's belief that $\mathrm{P}$ would be only accidentally true; e.g., circumstances in which were one to believe that this - what one sees - is a barn, one's belief would be only accidentally true, because every other barn-like object in the vicinity is a façade; in these circumstances, even though one sees that $\mathrm{P}$, one is not in a position to know that $\mathrm{P}$, or in a position to know that one sees that $\mathrm{P}$. For if one was in a position to know that $\mathrm{P}$ then one would know that $\mathrm{P}$ if one were to believe that $\mathrm{P}$ because one sees that $\mathrm{P} .{ }^{14}$ But, in these circumstances, one cannot know that $\mathrm{P}$. And if one was in a position to know that one sees that $\mathrm{P}$, then one would know that one sees that $\mathrm{P}$ if one were to believe that one sees that $\mathrm{P}$ because one sees that $\mathrm{P} .{ }^{15} \mathrm{But}$, in these circumstances, one cannot know that one sees that $\mathrm{P}$, because if one could know this then one could know that $\mathrm{P}$ - and in these circumstances, one cannot know that $\mathrm{P}$.

The obvious response to this worry - one which is already contained in McDowell's epistemological writings - is that, in these circumstances, one cannot see that P; e.g., one can see a barn, but one cannot see that this is a barn, precisely because, in these barn-façade-heavy circumstances, one cannot know that it is a barn (McDowell 1982, 390, n. 37). However, one might worry that this response is distorting our linguistic practice, so as to fit it into a mould forged by a prior philosophical theory of perceptual knowledge. And if this worry takes hold, the disjunctive conception of perceiving can come to the rescue. According to this conception, cases of perceiving that $\mathrm{P}$ either supply one with a reason consisting in the fact that one perceives that $\mathrm{P}$, because they are cases in which one is in a position to know that one perceives that $\mathrm{P}$, or supply one with a reason consisting merely in the fact that one seems to perceive that $\mathrm{P}$, because they are cases in which one merely perceives that P, i.e., cases in which, even though one perceives that $\mathrm{P}$, one is not in a position to know that one perceives that $\mathrm{P}$. Were we to grant this conception, we would prevent the worry from arising, by allowing for the possibility of cases in which one perceives that $\mathrm{P}$ but is not in a position to know that one perceives that P. But we would prevent the worry from arising without insisting - as 
McDowell himself insists - that (e.g.) one simply cannot see that this is a barn, in the barn-façade-heavy circumstances.

I think there is something to this worry. But I do not want to place much weight on it, in part because I am not sure it merits much weight, but centrally because I think there is a more serious worry, which better serves to motivate the disjunctive conception of perceiving. 16

5. McDowell's luminosity claim is so-called because it is an instance of a general claim which has come to be known as luminosity. And there are reasons to be suspicions of luminosity. These reasons tend to be cast in the form of a rather technical-looking argument, but they can be stated quite simply. ${ }^{17}$

First, let us assume something markedly stronger than the present claim. Let us assume an instance of what we might call 'super-luminosity', i.e., if one sees that $\mathrm{P}$, then one knows that one sees that $\mathrm{P}$ - or, more precisely, for any time $\mathrm{t}$, if at $\mathrm{t}$ one sees that $\mathrm{P}$ then at $\mathrm{t}$ one knows that one sees that $\mathrm{P}$. And second, let us assume a certain sort of reliability principle for knowledge: for any times $t$ and $t+1$, where $t$ and $t+1$ are any two times spaced only fractionally - say, one millisecond - apart, if at t one knows that something is the case, then at $\mathrm{t}+1$ this very thing is the case; e.g., if at $\mathrm{t} I$ know that I see that your sweater is brown, then at $\mathrm{t}+1$ I see that your sweater is brown. Now imagine a stretch of time between two intervals, at the beginning of which I see that your sweater is brown, but at the end of which I do not (perhaps this is a stretch of time during which your sweater is slowly starting to look a different colour, because the lights which make it impossible to tell the colours of things are slowly turning on). And let ' $t_{i}$ ' stand for the first interval, ' $t_{i+n}$ ' stand for the second interval, and ' $t_{i+1}$ ', ' $t_{i+2}$ ', ' $t_{i+3}$ ' .. and so on stand for each millisecond of time between these two intervals. At $t_{i} I$ see that your sweater is brown. Given the super-luminosity claim, at $t_{\mathrm{i}} \mathrm{I}$ know that I see that your sweater is brown. So, given the reliability principle, at $t_{i+1}$ I see that your sweater is brown. And given the super-luminosity claim, at $\mathrm{t}_{\mathrm{i}+1} \mathrm{I}$ know that I see that your sweater is brown. So, given the reliability principle, at $t_{i+2}$ I see that your sweater is brown. And given the super-luminosity claim, at $\mathrm{t}_{\mathrm{i}+2} \mathrm{I}$ know that I see that your sweater is brown. So, given the reliability principle, at $t_{i+3}$ I see that your sweater is brown. And so on. The upshot is that 
at $t_{i+n}$, I see that your sweater is brown. But, by hypothesis, at $t_{i+n} I$ do not see that your sweater is brown. As we might put it: the upshot is that I see that your sweater is brown during the whole of the relevant stretch of time. And that is absurd, because by hypothesis I do not see that it is brown at the end of the relevant stretch.

It seems that either the super-luminosity claim or the reliability principle must be relinquished. Suspicion immediately falls onto the super-luminosity claim, given that it is stronger than McDowell's luminosity claim, which says only that if one sees that $\mathrm{P}$ then one is in a position to know that one sees that $\mathrm{P}$ - or, more precisely, that for any time $\mathrm{t}$, if at $\mathrm{t}$ one sees that $\mathrm{P}$ then at $\mathrm{t}$ one is in a position to know that one sees that $\mathrm{P}$. But it seems that replacing super-luminosity by luminosity will not scotch the absurd upshot.

This is especially easy to see if we work with the way of understanding the idea of being in a position to know which discussions of the anti-luminosity argument tend to assume, according to which if I am in a position to know that something is the case, and I attend to the question of whether this is the case, then I know that it is the case. We need simply to imagine our stretch of time between two intervals - at the beginning of which I see that your sweater is brown, but at the end of which I do not - and to insist that throughout all of this stretch of time I am attending to the question of whether I see that your sweater is brown. For now - on the assumption that $\mathrm{t}$ is a time during the relevant stretch (including the two intervals) - the luminosity claim that, for any time $t$, if at $t$ I see that your sweater is brown then at $\mathrm{t} I$ am in a position to know that I see that your sweater is brown, will entail the super-luminosity claim that, for any time $t$, if at $t$ I see that your sweater is brown then at $\mathrm{I}$ I know that I see that your sweater is brown. So, it will still follow - given the reliability principle - that I see that your sweater is brown during the whole of the relevant stretch of time. And this is absurd, because by hypothesis I do not see that it is brown at the end of the relevant stretch.

However, there is no need for us to employ this way of understanding the idea of being in a position to know, because the absurd conclusion will follow even if we work with the way of understanding this idea which McDowell favours. We need simply to imagine our stretch of time between two intervals - at the beginning of which I am seeing that your sweater is brown, but at the end of which I am not - and to insist that, for any time $t$, where $t$ is a time during this stretch (including the two intervals), if at $t$ see that 
your sweater is brown, then at $\mathrm{I}$ I believe that I see that your sweater is brown because I see that your sweater is brown. ${ }^{18}$ For now - on the assumption that $\mathrm{t}$ is a time during the relevant stretch (including the two intervals) - the luminosity claim that, for any time $t$, if at $\mathrm{t} I$ see that your sweater is brown then at $\mathrm{t} I$ am in a position to know that I see that your sweater is brown, will, once again, entail the super-luminosity claim that, for any time $\mathrm{t}$, if at $\mathrm{t} I$ see that your sweater is brown then at $\mathrm{t} I$ know that I see that your sweater is brown. So, it will still follow - given the reliability principle - that I see that your sweater is brown during the whole of the relevant stretch of time. And this is absurd, because by hypothesis I do not see that your sweater is brown at the end of the stretch.

Once disabused both of the illusion that the anti-luminosity argument does not touch McDowell's luminosity claim but merely the super-luminosity claim, and of the related illusion that it will not touch the former once the idea of being in a position to know is understood in the way McDowell recommends, suspicion naturally falls onto the reliability principle - and indeed this has been the standard target for suspicion. ${ }^{19}$

There is no space here for a full-scale defence of this principle (and I would not know how to provide one even if there was). But I think there is a ladder of thought, leading all the way up to this principle, which is sufficiently appealing that any argument for rejecting the principle, no matter how compelling, will seem to land one in the dialectically unattractive position of denying one of the steps in this ladder.

The following constitutes a seemingly general requirement on knowledge: if one knows that something is the case, then one believes that it is the case because it is the case - where the 'because' is the 'because' of some species of causal explanation. This requirement appears, in the case of perceptual knowledge, in the form of the thought that if one knows (perceptually) that something is the case then one believes that it is the case because one perceives that it is the case (and so, because it is the case). And it appears, in the case of knowledge that one perceives that something is the case, in the form of the thought that if one knows that one perceives that something is the case then one believes that one perceives that it is the case because one perceives that it is the case. Now it seems that, if in one situation something is the case and one believes that it is the case, but in a very close situation it is not the case and yet one still believes that it is the case, then the claim that, in the former situation, one believes that it is the case because it is the 
case is in jeopardy. And if this claim is jeopardised then so is the claim that, in the former situation, one knows that it is the case - given the seemingly general requirement on knowledge. So, it seems - given this requirement - that if in one situation one knows that something is the case, but in a very close situation this thing is not the case, then in this very close situation one does not believe that this thing is the case.

What is it for two situations to count as being 'very close'? Well, it seems to be a fact about our capacity for altering confidence-levels that we cannot, across a fractionally small space of time (say, a single millisecond) shift from a state of believing that something is the case with the confidence required for knowing that it is the case, to a state of not believing that it is the case. And here by 'our capacity' I mean the capacity of human beings like us, who are at our current stage of biological development, and who maintain their confidence-levels without the benefit of special scientific instrumentation. We might cast this fact into hypothetical form by saying that, if at one time one knows (and so believes) that something is the case, then at a fractionally later time (say, one millisecond later) one still believes that it is the case - other things being equal, of course, i.e., so long as one still exists at the later time, and still exists as the ordinary human being one is. Given this, it seems that two situations temporally spaced only fractionally (say, one millisecond) apart will always count, for human beings, as being 'very close', no matter how much the situations may differ in other respects. We can make this point vivid - in a way which exploits the principle enunciated at the end of the previous paragraph (the principle which seems to flow from the seemingly general requirement on knowledge) - by saying that a world in which nothing is the case for any longer than one millisecond would be a world in which we cannot know anything. ${ }^{20}$ Things would zip by too quickly for us to believe that they are the case because they are the case.

And with that, we arrive at the anti-luminosity argument's reliability principle. For when we combine this understanding of the idea of a 'very close' situation with the principle which seems to flow from the general requirement on knowledge, we arrive at the principle that if in one situation one knows that something is the case, but in a situation temporally spaced only fractionally (say, one millisecond) apart from the former situation this thing is not the case, then in the latter situation one does not believe that it is the case. And it follows from the conjunction of this principle, and the hypothetical into 
which the aforesaid fact about our capacity for altering confidence-levels was cast, that if in one situation one knows that something is the case then in a situation temporally spaced only fractionally (say, one millisecond) apart from the former situation this thing $i s$ the case. In other words, what follows is the reliability principle. $^{21}$

So, it seems anyone who disputes the reliability principle of the anti-luminosity argument will be in the unattractive position of disputing one of the steps in this ladder of thought, be it the seemingly general requirement on knowledge, or the principle which seems to flow from this requirement, or the apparent fact about our capacity for altering confidence-levels, or the understanding of the idea of a 'very close' situation which this apparent fact seems to entrain. That is hardly enough to compel acceptance of the reliability principle, even when it is understood as a principle which applies merely to the knowledge enjoyed by ordinary human beings like us. But it ought to be enough to caution against rejecting the principle - so understood - and, as a result, enough to caution against rejecting the anti-luminosity argument to which it is essential.

6. The upshot is that we have some reason to reject luminosity, and as a result some reason to reject McDowell's luminosity claim.

The fact that there is some reason to reject this luminosity claim means there is some reason to endorse the disjunctive conception of perceiving. For if we are to reject this claim, we shall need to reject one of the two thoughts which together entail it, i.e., either McDowell's thought that if I am entitled to believe that $\mathrm{P}$ then I am in a position to know what entitles me to believe that $\mathrm{P}$, or his thought that if I perceive that $\mathrm{P}$ then I am entitled to believe that $\mathrm{P}$ by the fact that I perceive that $\mathrm{P}$. The first of these thoughts McDowell's anti-externalist, Sellarsian thought - is not in dispute here, because this thought is fundamental to McDowell's conception of "knowledge - at least as it is enjoyed by rational animals - [as] a certain sort of standing in the space of reasons". So, we shall need to reject the second of these thoughts (given that we reject the luminosity claim). It seems to me that a great strength of the disjunctive conception of perceiving is that it enables us to reject this second thought without relinquishing either the first thought (the Sellarsian thought), or McDowell's contention that - on some occasions one can be entitled to believe that $\mathrm{P}$ by the fact that one perceives that $\mathrm{P}$. 
According to the disjunctive conception, cases of perceiving that $\mathrm{P}$ are either cases of being in a position to know that one perceives that $\mathrm{P}$, or cases of merely perceiving that $\mathrm{P}$. If one perceives that $\mathrm{P}$, and the case of perceiving that $\mathrm{P}$ which one enjoys is of the former variety, then one can be entitled to believe that $\mathrm{P}$ by the fact that one perceives that $\mathrm{P}$, because one is in a position to know that one perceives that $\mathrm{P}$. Whereas, if one perceives that $\mathrm{P}$, and the case of perceiving that $\mathrm{P}$ which one enjoys is of the latter variety, then one cannot be entitled to believe that $\mathrm{P}$ by the fact that one perceives that $\mathrm{P}$, because one is not in a position to know that one perceives that $\mathrm{P}$.

It is precisely by allowing for the possibility of merely believing that $\mathrm{P}$ that the disjunctive conception avoids the luminosity argument. For given the disjunctive conception, the following is possible: at $\mathrm{t}$ I know that I see that your sweater is brown, and so - given the reliability principle of the anti-luminosity argument - at $\mathrm{t}+1$ I see that your sweater is brown; but at $\mathrm{t}+1$ I do not know that I see that your sweater is brown (even though at $\mathrm{t}+1 \mathrm{I}$ believe that I see that your sweater is brown because I see that your sweater is brown) precisely because when at $\mathrm{t}+1$ I see that it is brown I merely see that it is brown. No general claim is being made to the effect that, for any time $t$, if at $\mathrm{t}$ see that $\mathrm{P}$ then at $\mathrm{t} \mathrm{I}$ am in a position to know that I see that $\mathrm{P}$. So, the threat that I will never stop seeing that your sweater is brown throughout the relevant stretch of time is no longer present. (If this is not yet clear, just imagine a millisecond in the stretch when the case of seeing that your sweater is brown which I enjoy is a case of being in a position to know that I see that your sweater is brown. And assume both McDowell's way of understanding the idea of being in a position to know, and that whenever I see that your sweater is brown I believe that I see that your sweater is brown because I see that your sweater is brown. Given the reliability principle, it follows that at the next millisecond I still see that your sweater is brown. But because the luminosity claim has been replaced by the disjunctive conception, it is possible that, at this millisecond, the case of seeing that your sweater is brown which I enjoy is a case of merely seeing that your sweater is brown, and, consequently, possible that at this millisecond I do not know that I see that your sweater is brown. If this possibility is actualised, then it is not the case, at this millisecond, that I know that I see that your sweater is brown, even though it is the case, at this millisecond, that I see that your sweater is brown.) But even though this threat is 
scotched, neither the Sellarsian thought (i.e., that if I am entitled to believe that P then I am in a position to know what entitles me to believe that $\mathrm{P}$ ) nor the contention that - on some occasions - one can be entitled to believe that $\mathrm{P}$ by the fact that one perceives that $\mathrm{P}$ is relinquished.

7. However, it does seem that the disjunctive conception of perceiving, as it stands, leaves us in the dark on a crucial point. It claims that some cases of perceiving that $\mathrm{P}$ are cases of being in a position to know that one perceives that P; but it seems not to tell us what it is about these cases which makes them cases of being in a position to know that one perceives that $\mathrm{P}$. Put differently, it seems not to tell us what puts one in a position to know that one perceives that $\mathrm{P}$ (when one is in this position). It seems merely to tell us that some cases of perceiving that $\mathrm{P}$ are cases of being in a position to know that one perceives that $\mathrm{P}$, without explaining what makes these cases instances of this kind.

There are at least two ways of enriching the disjunctive conception so that it supplies the needed illumination.

The first maintains that some cases of perceiving that $\mathrm{P}$ are constituted as cases of being in a position to know that one perceives that $\mathrm{P}$ because of something extrinsic to themselves, i.e., because of one's possession of a (fallible) capacity to know that one perceives that $\mathrm{P}$. Some cases of perceiving that $\mathrm{P}$ count as cases of being in a position to know that one perceives that $\mathrm{P}$ because, in these cases, one possesses the capacity; whereas other cases of perceiving that $\mathrm{P}$ count as cases of merely perceiving that $\mathrm{P}$ because, in these cases, one does not possess the capacity. So, what puts one in a position to know that one perceives that $\mathrm{P}$ is not the fact that one perceives that $\mathrm{P}$ by itself, but this fact against the background of one's possession of this capacity. ${ }^{22}$

By contrast, the second maintains that some cases of perceiving that $\mathrm{P}$ are intrinsically cases of being in a position to know that one perceives that $\mathrm{P}$; they are not constituted as such cases by something extrinsic to themselves, rather, it is intrinsic to them that the subject who enjoys them possesses the capacity to know that they perceive that $\mathrm{P}$. Whereas, on the first enrichment, no case of perceiving that $\mathrm{P}$ is intrinsically such that one could enjoy it only if one possesses this capacity, on the second enrichment some cases of perceiving that $\mathrm{P}$ are intrinsically such that one could enjoy them only if one 
possesses this capacity. Cases of perceiving that $\mathrm{P}$ come in at least two sorts: those which are intrinsically cases of being in a position to know that one perceives that $\mathrm{P}$, and those which are cases of merely perceiving that $\mathrm{P}$, i.e., cases in which one is not in a position to know that one perceives that $\mathrm{P}^{23}$ So, what puts one in a position to know that one perceives that $\mathrm{P}$ is not the fact that one perceives that $\mathrm{P}$ against the background of one's possession of the capacity, but the fact that one perceives that $\mathrm{P}$ by itself - where this is a fact to the effect that one enjoys a case of perceiving that $\mathrm{P}$ of the first sort.

Armed with the distinction between these two different enrichments of the disjunctive conception of perceiving, the question seems to arise as to which we should endorse. But before turning to that, we need to consider a seemingly more pressing issue.

8. In $\S 4$, I mentioned the worry that there are circumstances in which one can see that $P$ without being in a position to know (visually) that $\mathrm{P}$, e.g., barn-façade scenarios. But there will be those who refuse to feel this worry. There will be those who agree with McDowell that the very idea of seeing that $\mathrm{P}$ is the idea of being in a position to know (visually) that $\mathrm{P}^{24}$ And there will be those who think, contra McDowell, that the idea of seeing that $\mathrm{P}$ is the idea, not merely of being in a position to know (visually) that $\mathrm{P}$, but of knowing (visually) that $\mathrm{P} .{ }^{25}$ To the latter, much of the foregoing - which has followed McDowell in taking seeing that $\mathrm{P}$ to fall short of knowing (visually) that $\mathrm{P}$ - will have seemed rather odd. But even to the former, the claim that there can be cases of seeing that $\mathrm{P}$ which are neither cases of knowing (visually) that $\mathrm{P}$, nor cases of being in a position to know (visually) that $\mathrm{P}$, will have seemed odd. (To the latter this claim will have seemed odder still.) And the disjunctive conception entails this claim, given the following plausible thoughts, both of which McDowell endorses, and neither of which I wish to deny: first, that if I am in a position to know (perceptually) that P then I am entitled to believe that $\mathrm{P}$ by the fact that I perceive that $\mathrm{P}$; and, secondly, that if I am entitled to believe that $\mathrm{P}$ by the fact that I perceive that $\mathrm{P}$, then I am in a position to know that I perceive that P. For the disjunctive conception insists that there are cases in which I perceive that $\mathrm{P}$ but am not in a position to know that $\mathrm{I}$ perceive that $\mathrm{P}$ (i.e., cases in which I merely perceive that P). So, because I am not in a position to know that I perceive that $\mathrm{P}$, in these cases, it follows - given both of the aforesaid plausible thoughts 
- that, in these cases, I am not in a position to know (perceptually) that P. And so, it follows that there can be (e.g.) cases of seeing that $\mathrm{P}$ which are not cases of being in a position to know (visually) that $\mathrm{P}$. And McDowell will find that thought rather odd.

This ostensible oddness might seem to put pressure on the disjunctive conception. But why not see it instead as putting pressure on McDowell's assumption that the entitlement which I have, when I enjoy perceptual knowledge, consists in the fact that I perceive that P? I noted (in §2) that this assumption diverges from the policy I adopted in $\S 1$, of treating this entitlement as consisting in the fact that I perceive such-and-such, rather than in the fact that I perceive that P, e.g., in the fact that I perceive a man in front of me chewing on his pencil, rather than in the fact that I perceive that there is a man in front of me chewing on his pencil. Perhaps the frame in which the disjunctive conception should ideally emerge is one constituted by this policy, rather than by McDowell's assumption. This policy does not dispute McDowell's central contention that the reason required for perceptual knowledge must not fall short of the fact known; e.g., I cannot see a man in front of me chewing on the end of his pencil unless there is a man in front of me chewing on the end of his pencil. But replacing McDowell's assumption by this policy will remove the ostensible oddness attaching to the disjunctive conception of perceiving.

To illustrate: if I have perceptual knowledge that your sweater is brown, then I have a reason to believe that your sweater is brown, consisting in the fact that I see your brown sweater. Of course, I can see your brown sweater without knowing that your sweater is brown. But, at least from McDowell's perspective, this is no objection to thinking that the fact that I see your brown sweater cannot be an entitlement, or a reason, which I have to believe that your sweater is brown. And this is because - for McDowell - I can see that your sweater is brown without knowing that your sweater is brown, precisely because I am in what Kern calls "reflectively unfavourable circumstances" (see §3). What is more, it does not follow from the fact that I can see your brown sweater without being in a position to know that your sweater is brown that the fact that I see your brown sweater cannot function as a reason for me to believe that your sweater is brown. We just need to insist that in order for it to function as such a reason I need to be in a position to know that I see your brown sweater. For if I am in a position to know that I see your brown sweater, how can I fail to be in a position to know that your sweater is 
brown? From the mere fact that I see your brown sweater it may not follow that I am in a position to know that your sweater is brown. But if this fact functions as a reason which I have to believe that your sweater is brown, then it does follow that I am in this position.

The general idea is that, if I enjoy perceptual knowledge that $\mathrm{P}$, then I believe that $\mathrm{P}$ for a reason consisting in the fact that I perceive such-and-such - where what replaces 'such-and-such' suitably matches what replaces ' $\mathrm{P}$ '. There is probably no principle the application of which unfailingly guarantees the presence of a suitable match here. But the following seems a good rule of thumb: take the proposition which replaces ' $\mathrm{P}$ ', and remove its marks of proposition-hood, such as its quantifiers and its logical connectives; e.g., if what replaces ' $\mathrm{P}$ ' is the proposition there is a man in front of me, then what replaces 'such-and-such' will be a man in front of me. (Subtlety may be required when applying this rule; e.g., if what replaces ' $\mathrm{P}$ ' is your sweater is brown, what replaces 'such-and-such' will be your brown sweater; whereas, if what replaces 'P' is that parrot is dead, what replaces 'such-and-such' will be a dead parrot.)

For this suggestion to be defensible we need some idea about what puts one in a position to know that one perceives such-and-such, when one is in this position. And here the disjunctive conception of perceiving can do its work - where this is understood not as the disjunctive conception of perceiving that $\mathrm{P}$, but as the disjunctive conceptions of perceiving such-and-such. (And in doing this work it can seem to suggest an answer to the question raised at the close of $\S 7$, i.e., it can seem to suggest that we should endorse the extrinsic rather than the intrinsic enrichment.)

The disjunctive conception of perceiving such-and-such - on both its intrinsic and its extrinsic enrichments - maintains that cases of perceiving such-and-such either supply one with a reason consisting in the fact that one perceives such-and-such, because they are cases of being in a position to know that one perceives such-and-such, or supply one with a reason consisting in the fact that one seems to perceive such-and-such, because they are cases of merely perceiving such-and-such, i.e., cases of perceiving such-andsuch which are not cases of being in a position to know that one perceives such-and-such.

The extrinsic enrichment maintains that what puts one in the relevant position is the fact that one perceives such-and-such together with one's possession of an epistemic capacity, which we can specify as the capacity to tell that what one perceives is such-and- 
such; e.g., the capacity to tell that what one perceives is your brown sweater. Putting it like that brings out how this is a capacity at once to know one's reason to believe that $\mathrm{P}$ and to know perceptually that P, e.g., at once to know that one perceives your brown sweater, and to know perceptually that your sweater is brown. For if I can tell that I perceive your brown sweater, how can I fail to be in a position to know that your sweater is brown? That one possesses this capacity is not guaranteed by the fact that one perceives such-and-such. But if one perceives such-and-such, and one possesses this capacity, then one is in a position to know (e.g.) that one perceives such-and-such. ${ }^{26}$ According to the intrinsic enrichment, by contrast, that one possesses the capacity to tell that what one perceives is such-and-such is guaranteed by the fact that one perceives such-and-such - where this is a fact to the effect that the case of perceiving such-and-such which one enjoys is of the first rather than the second of the following sorts. For cases of perceiving such-and-such come in at least two sorts: some are intrinsically cases of being in a position to know that one perceives such-and-such (for it is intrinsic to them that one possesses the capacity to tell that what one perceives is suchand-such); whereas others are cases of merely perceiving such-and-such.

It should be clear that, unlike the disjunctive conception of perceiving that $\mathrm{P}$, which did entail the ostensibly odd thought that one can (e.g.) see that $\mathrm{P}$ without being in a position to know (visually) that $\mathrm{P}$, the new disjunctive conception of perceiving suchand-such does not carry this entailment (regardless of whether it is enriched in the extrinsic or the intrinsic direction). For consider the following two plausible thoughts, cousins of the two plausible thoughts mentioned in the first paragraph of this section: first, if one is in a position to know perceptually that $\mathrm{P}$ then one is entitled to believe that $\mathrm{P}$ by the fact that one perceives such-and-such; secondly, if one is entitled to believe that $\mathrm{P}$ by the fact that one perceives such-and-such then one is in a position to know that one perceives such-and-such (where, in each case, what replaces 'such-and-such' suitably matches what replaces 'P'). Given these plausible thoughts, the new disjunctive conception entails that there are cases in which one perceives such-and-such but is not in a position to know (perceptually) that $\mathrm{P}$. But there is nothing even ostensibly odd about this thought. (The thought that I can (e.g.) see a man in front of me, but not be in a position to know (visually) that there is a man in front of me is routine.) What is more, 
there is no obvious route from this thought to the ostensibly odd thought that one can perceive that $\mathrm{P}$ but not be in a position to know (perceptually) that $\mathrm{P}$. Indeed, it seems that, now that we have replaced the disjunctive conception of perceiving that $\mathrm{P}$ with the disjunctive conception of perceiving such-and-such, we are free to use the idea of perceiving that $\mathrm{P}$ either in such a way that if one perceives that $\mathrm{P}$ then one actually knows (perceptually) that $\mathrm{P}$, or in such a way that if one perceives that $\mathrm{P}$ then one is in a position to know (perceptually) that P. Nothing in the new disjunctive conception of perceiving such-and-such, even when it is conjoined with some or even all of the aforesaid plausible thoughts, will prevent one from using the idea of perceiving that $\mathrm{P}$ in either of these ways.

However, there can seem to be a problem with the intrinsic enrichment of the new disjunctive conception of perceiving. In insisting that some facts to the effect that one perceives such-and-such guarantee that one possesses the relevant epistemic capacity, the intrinsic enrichment does not contradict the obvious point that I can (e.g.) see your brown sweater without being in a position to know that I see your brown sweater, because it allows for other facts to this effect which do not guarantee this (because, e.g., they are facts to the effect that one enjoys a case of perceiving such-and-such which is in fact a case of merely perceiving such-and-such). But it can be tempting to move from this obvious point to the distinct - but, for some it seems, no less obvious - point that no fact to the effect that one perceives such-and-such can entail that one possesses the capacity to know that one perceives such-and-such. Facts to the effect that one perceives that $P$ guarantee that one possesses the capacity to know perceptually that $\mathrm{P}$; but facts to the effect that one perceives such-and-such are different, because - unlike cases of perceiving that $\mathrm{P}$ - cases of perceiving such-and-such are non-epistemic, i.e., no such case is intrinsically an opportunity to know anything; and so, no such case is something to which the possession of an epistemic capacity is intrinsic. ${ }^{27}$

The intrinsic enrichment sets its face against this supposedly obvious point. This might seem to show that we should reject this way of enriching the disjunctive conception. But that might be too quick. I do not propose to settle this matter here. But I want to end by showing that in this respect the intrinsic enrichment is in line with a recent thought of McDowell's, which rejects the very idea of non-epistemic seeing. 
9. In a recent essay, McDowell (2008) insists that seeing such-and-such - as it is enjoyed by rational animals - requires the possession of suitable conceptual capacities on the part of the perceiving subject; specifically, conceptual capacities associated with concepts of "proper sensibles of sight and common sensibles accessible to sight" (260) - concepts of (e.g.) colours, and shapes. This is required to ensure that cases of seeing such-and-such are intrinsically opportunities to know that what one sees exhibits certain sensibles. Which sensibles these are depends not just on which sensibles are exhibited by what one sees but on which conceptual capacities are drawn into operation in the case of seeing which one enjoys. The idea is that a case of seeing something which exhibits a certain sensible, in which the conceptual capacity associated with the concept of this sensible is suitably drawn into operation, is intrinsically an opportunity to know that what one sees exhibits this sensible. It is taken for granted that, in every case of seeing, some conceptual capacities associated with concepts of the relevant sensibles are suitably drawn into operation. And it is taken for granted that the fact that such-and-such conceptual capacities are suitably operative, in a particular case of seeing, is itself an intrinsic feature of the case of seeing in question.

Insisting on these points is consistent with denying (as McDowell does deny) that cases of seeing are intrinsically opportunities to know more sophisticated things. E.g., no case of seeing your brown sweater is intrinsically an opportunity to know that I see your brown sweater; my being in a position to know that always requires the extrinsic presence of the capacity to tell that what I see is your sweater. However, he thinks that my being in a position to know that I see something brown need not require the extrinsic presence of the capacity to tell that what I see is something brown; I could be in that position simply by seeing (e.g.) your brown sweater, so long as when I do the conceptual capacity associated with the concept brown is suitably drawn into operation.

What we have here is a glimpse of a disjunctive conception of perceiving (or at least, a disjunctive conception of seeing), enriched in the intrinsic way. Some cases of seeing something brown are intrinsically cases in which the conceptual capacity associated with the concept brown is suitably drawn into operation, whereas other cases of seeing something brown are not intrinsically cases in which the conceptual capacity 
associated with this concept is suitably operative. The former are intrinsically cases of being in a position to know that one sees something brown. The latter need not be cases of merely seeing something brown; but if they are cases of being in a position to know that one sees something brown, the reason why they possess this status must be different from the reason why this status is possessed by cases of the former sort.

Of course, we do not arrive at a disjunctive conception of seeing such-and-such until we insist on there being cases of merely seeing such-and-such. Nothing in McDowell's recent thought shows that he endorses such a conception. (This is why I only said that what we have here is a glimpse of a disjunctive conception of seeing.) But it seems that McDowell ought to allow for cases of merely seeing something brown, so as to avoid another luminosity claim, i.e., the claim that if one sees something brown then one is in a position to know that one sees something brown. And what goes for brownness goes for every other sensible which one can see.

So, if McDowell's recent thought is on the right lines, then, on pain of the antiluminosity argument, he has reason to endorse the disjunctive conception of perceiving, on its intrinsic enrichment, for cases of seeing something which exhibits a certain sensible. That is, he has reason to think that such cases come in at least two sorts: those which are intrinsically cases of being in a position to know that one sees something exhibiting the relevant sensible (because the relevant conceptual capacities are suitably drawn into operation), and those which are cases of merely seeing something exhibiting the relevant sensible. But for all his recent thought has to say, the disjunctive conception, on its extrinsic enrichment, can apply to cases of seeing, e.g., your brown sweater. Whether his recent thought is on the right lines is a topic for a different essay (although I happen to think it is). The aim, at this late stage, is merely to present a consideration arising from McDowell's own writings - which tells in favour of the intrinsic enrichment of the disjunctive conception, at least for some cases of seeing such-and-such.

10. We are now in a position to express the disjunctive conception of perceiving as follows: cases of perceiving such-and-such can either supply one with a reason consisting in the fact that one perceives such-and-such, because they are - perhaps intrinsically, or perhaps extrinsically - cases of being in a position to know that one perceives such-and- 
such, or supply one with a reason consisting merely in the fact that one seems to perceive such-and-such, because they are cases of merely perceiving such-and-such, i.e., cases in which, though one perceives such-and-such, one is not in a position to know one does so.

This way of putting things enables us to press the question of the relation between the disjunctive conception of perceiving and McDowell's original disjunctive conception of experience; specifically, whether the former should be thought to supplement, or to supplant the latter. The latter says that experience can supply one with a reason consisting either in the fact that one perceives such-and-such, or merely in the fact that one seems to do so. I suggest that we think of the disjunctive conception of perceiving as offering an account of what it is for one's experience actually to supply one with the former reason, i.e., it is not enough for one's experience to be a case of perceiving suchand-such; it must be a case of perceiving such-and-such of a certain sort, one which is be it intrinsically, or extrinsically - a case of being in a position to know that one perceives such-and-such, as opposed to (what I call) a case of mere perceiving. That is the nub of the conception which it has been my aim to recommend in this essay.

\section{Acknowledgements}

I would like to thank Jane Calvert, Jennifer Hornsby, John McDowell, Alan Millar, and Marcus Willaschek for their very helpful comments on earlier versions of this essay.

\section{Notes}

1. Here I follow John McDowell's presentation of this variant, in his 1982.

2. For an extended defence of this way of understanding McDowell, see Haddock and Macpherson 2008a.

3. See especially Martin 2002, and many of the essays collected in the first part of Haddock and Macpherson 2008b.

4. As far as I am aware, Alex Byrne and Heather Logue were the first clearly to distinguish between epistemological and metaphysical versions of the disjunctive conception of experience; see their 2008. See also Millar 2007.

5. This is Martin's view. For a comprehensive discussion, see Soteriou 2009.

6. By way of doing even more to distance McDowell's disjunctive conception from the 
metaphysical disjunctive conception, let me note that, even though McDowell makes use of the idea of experiences which are 'just like' one another, it is not obvious that this idea must be understood in terms either of the idea of sameness of phenomenology, or in terms of the idea of what is knowable by introspection alone. McDowell (2006a) remarks that even though "the claim that from a subject's point of view, a misleading experience can be indistinguishable from a case in which things are as they appear ... might be taken as a self-standing claim about the phenomenology of misleading appearance, available to be cited in explaining the fact that subjects can be misled by appearances ... the right way to take it is as registering the fact that, on that interpretation, it is supposed to explain: the undeniable fact that our capacity to get to know things through perception is fallible" (231). I will say more about the idea of a fallible capacity to know things through perception as I proceed. But for now the point to note is that to say that my experience in the good case is 'just like' my experience in the bad case might be merely to say that it can be reasonable for me to take it that my experience is good (e.g., I am seeing a man chewing on his pencil) when in fact my experience is bad (e.g., I am hallucinating such a man). Perhaps the notions of introspection and phenomenology need not figure in the epistemological disjunctive conception.

7. Because it is often missed; for some relevant discussion, see Neta and Pritchard 2007.

8. Here McDowell differs from those philosophers - e.g., Tyler Burge, and Alvin Plantinga - who put some of these notions (e.g., the notions of entitlement and justification, in Burge's case, and the notions of warrant and justification, in Plantinga's) to specific, technical uses. There is a useful remark on one instance of this technical tendency in McDowell 2006b, 132, n. 4.

9. An apparent exception is McDowell 2008, to be discussed in $\S 9$ below.

10. We arrive at least at this claim. There are two ways to understand the Sellarsian thought which are relevant in the present context: as the thought that if I am entitled to believe that $\mathrm{P}$ by the fact that $\mathrm{Q}$ then I am in a position to know that Q; and, as the thought that if I am entitled to believe that $\mathrm{P}$ by the fact that $\mathrm{Q}$ then $\mathrm{I}$ am in a position to know that $\mathrm{I}$ am entitled to believe that $\mathrm{P}$ by the fact that $\mathrm{Q}$. If we understand it in the first way, then we arrive precisely at this claim. But if we understand it in the second way, then we arrive at the stronger claim that if I am entitled to believe that $\mathrm{P}$ by the fact that I perceive that $\mathrm{P}$ then I am in a position to know that I am entitled to believe that $\mathrm{P}$ by the fact that I perceive that $P$. (That is stronger because the truth of its consequent entails but is not 
entailed by the fact that I am in a position to know that I perceive that P.) For my purposes, it is enough that the Sellarsian thought enables us to arrive at the weaker claim; so, I propose to understand this thought in the first rather than the second of these ways.

11. A forerunner of the disjunctive conception of perceiving that $\mathrm{P}$ may be found in my contribution to Pritchard, Millar, and Haddock 2010. I think that many, if not all, of the claims which I make in this contribution, by means of this disjunctive conception of perceiving, can be made just as well - if not better - by means of the disjunctive conception of perceiving such-and-such which I sketch here.

12. More precisely, if one is in a position to know (perceptually) that $\mathrm{P}$ because one perceives that $\mathrm{P}$, then one knows (perceptually) that $\mathrm{P}$ if, and only if, one believes that $\mathrm{P}$ because one perceives that $\mathrm{P}$ - where that 'because' is the 'because' of the appropriate species of causal explanation.

13. More precisely, if one is in a position to know that one perceives that $\mathrm{P}$ because one perceives that $\mathrm{P}$, then one knows that one perceives that $\mathrm{P}$ if, and only if, one believes that one perceives that $\mathrm{P}$ because one perceives that $\mathrm{P}$ - where that 'because' is the 'because' of the appropriate species of causal explanation.

14. Where the 'because' is the 'because' of the appropriate species of causal explanation.

15. Where the 'because' is the 'because' of the appropriate species of causal explanation.

16. I mention this worry because I know that it moves some people, and for this reason hope that it might do something at least to begin to make clear the attractions of the disjunctive conception of perceiving.

17. The argument is due to Williamson 2000. Soteriou $(2009, \S 3.2)$ seems to me to go wrong in supposing that McDowell's (1986) claim that there are some facts about one's mind which one can know only fallibly is of a piece with Williamson's opposition to luminosity. For one thing, things which are only fallibly knowable might still be luminous. For another, Williamson thinks that (modulo some exceptions which are irrelevant for present purposes) nothing is luminous, whereas it seems that McDowell disagrees.

18. Where the 'because' is the 'because' of the appropriate species of causal explanation.

19. See, e.g., Neta and Rohrbaugh 2004.

20. Or at least, a world in which we cannot know anything which we can know to be the case only if we can believe that it is the case because it is the case - where the 'because' is the 'because' of some species of causal explanation. 
21. It might help to spell out more explicitly why this follows. Assume that $\mathrm{t}$ and $\mathrm{t}+1$ are two times spaced one millisecond apart, and that ' $\mathrm{C}$ ' refers to some specific thing which can be the case. And grant (1) if at $\mathrm{t}$ one knows that $\mathrm{C}$ is the case, and at $\mathrm{t}+1 \mathrm{C}$ is not the case, then at $\mathrm{t}+1$ one does not believe that $\mathrm{C}$ is the case (i.e., grant the principle which seems to follow from the seemingly general requirement on knowledge, fleshed out in line with the present understanding of the idea of being 'very close'); and, (2) if at t one knows that $\mathrm{C}$ is the case then at $\mathrm{t}+1$ one believes that $\mathrm{C}$ is the case (i.e., the hypothetical which purports to capture the putative fact about our capacity for altering confidencelevels). Now assume (3) at t one knows that $\mathrm{C}$ is the case. It follows from 2 and 3 that (4) at $\mathrm{t}+1$ one believes that $\mathrm{C}$ is the case. And it follows from 1 and 4 that (5) either at $\mathrm{t}$ one does not know that $\mathrm{C}$ is the case, or at $\mathrm{t}+1 \mathrm{C}$ is the case. And it follows from 3 and 5 , that (6) at $\mathrm{t}+1 \mathrm{C}$ is the case. So, it follows from 1 and 2 that (7) if at t one knows that $\mathrm{C}$ is the case then at $\mathrm{t}+1 \mathrm{C}$ is the case. In other words, the reliability principle follows from 1 and 2.

22. This claim will not lead to luminosity, given the disjunctive conception's insistence that the capacity at issue is a capacity one can lose even as one continues to perceive; e.g., a stretch of time in which I still see that your sweater is brown, but in which your sweater is slowly starting to look a different colour (because the dodgy lights are slowly turning on) can be one in which, at some time during it, I have lost this capacity, and so am not in a position to know that I see that your sweater is brown, even though I am still seeing that your sweater is brown (fractionally later, I will stop seeing that it is brown).

23. The reason why I do not formulate this second, intrinsic, enrichment as an exclusive disjunction - i.e., simply as the claim that cases of perceiving that $\mathrm{P}$ are either intrinsically cases of being in a position to know that one perceives that $\mathrm{P}$, or cases of merely perceiving that $\mathrm{P}$ - is because if I did then I would rule out those cases of perceiving that $\mathrm{P}$ which are extrinsically cases of being in a position to know that one perceives that $\mathrm{P}$. This point should be borne in mind, even though it will not be made a topic of discussion in what follows.

24. Rödl (2007, chapter 7) seems to be an example.

25. Williamson (2000, chapter 1$)$ seems to be an example.

26. This claim will not lead to luminosity, given the disjunctive conception's insistence that the capacity at issue is a capacity one can lose even as one continues to perceive; e.g., a stretch of time in which I still see your brown sweater but in which it is slowly starting to look a different colour can be one in which, at some time during it, I have lost this 
capacity, and so am not in a position to know that I see your brown sweater, even though I am still seeing your brown sweater (fractionally later, I will stop seeing it).

27. We seem to find a conception of perceiving such-and-such which is non-epistemic in this sense in Travis 2004.

\section{Notes on contributor}

Adrian Haddock is Lecturer in Philosophy at the University of Stirling. His publications include a number of essays on action, knowledge, and idealism, and (with Duncan Pritchard and Alan Millar) a monograph entitled The nature and value of knowledge: Three investigations (Oxford: Oxford University Press, 2010). He is also the editor (with Alan Millar and Duncan Pritchard) of Social epistemology (Oxford: Oxford University Press, 2010) and Epistemic value (Oxford: Oxford University Press, 2009), and (with Fiona Macpherson) of Disjunctivism: Perception, action, knowledge (Oxford: Oxford University Press, 2008).

\section{References}

Byrne, Alex, and Heather Logue. 2008. Either/ or. In Haddock and Macpherson eds. 2008, 57-94.

Haddock, Adrian, and Fiona Macpherson. 2008a. Introduction: Kinds of disjunctivism. In Haddock and Macpherson eds. 2008, 1-24.

Haddock, Adrian and Fiona Macpherson ed. 2008b. Disjunctivism: Perception, action, knowledge. Oxford: Oxford University Press.

Kern, Andrea. 2006. Quellen des wissens. Zum begriff vernünftiger erkenntnisfähigkeiten. Frankfurt/ Main: Suhrkamp.

Martin, M.G.F. 2002. The transparency of experience. Mind and Language, 17, no. 4: $376-425$.

McDowell, John. 1982. Criteria, defeasibility, and knowledge. Proceedings of the British Academy 68: 459-79. Reprinted in McDowell 1998, 369-94. [Page references to the reprint.]

McDowell, John. 1986. Singular thought and the extent of inner space. In Subject, thought, and context, ed. Philip Petit and John McDowell, 137-68. Oxford: Clarendon Press. Reprinted in McDowell 1998, 228-59.

McDowell, John. 1995. Knowledge and the internal. Philosophy and Phenomenological Research 55, no. 4: 877-93. Reprinted in McDowell 1998, 395-413. [Page references to the reprint.] 
McDowell, John. 1998. Meaning, knowledge, and reality. Cambridge, MA: Harvard University Press.

McDowell, John. 2003. Subjective, intersubjective, objective. Philosophical and Phenomenological Research 67, no. 3: 675-81. Reprinted in McDowell 2009b, 152-59. [Page references to the reprint.]

McDowell, John. 2006a. The disjunctive conception of experience as material for a transcendental argument. Teorema 25, no. 1: 19-33. Reprinted in McDowell 2009b, 22542. [Page references to the reprint.]

McDowell, John. 2006b. Conceptual capacities in perception. In Kreativität, ed. Günter Abel, 1065-79. Hamburg: Felix Meinar Verlag. Reprinted in McDowell 2009a, 127-44. [Page references to the reprint.]

McDowell, John. 2008. Avoiding the myth of the given. In John McDowell: Experience, norm, and nature, ed. Jakob Lindgaard, 1-14. Oxford: Wiley-Blackwell. Reprinted in McDowell 2009a, 256-72. [Page references to the reprint.]

McDowell, John. 2009a. Having the world in view: Essays on Kant, Hegel, and Sellars. Cambridge, MA: Harvard University Press.

McDowell, John. 2009b. The engaged intellect: Philosophical essays. Cambridge, MA: Harvard University Press.

Millar, Alan. 2007. What the disjunctivist is right about. Philosophy and Phenomenological Research 74, no. 1: 176-98.

Neta, Ram and Guy Rohrbaugh. 2004. Luminosity and the safety of knowledge. Pacific Philosophical Quarterly 85, no. 4: 396-406.

Neta, Ram and Duncan Pritchard. 2007. McDowell and the new evil genius. Philosophy and Phenomenological Research 74, no. 2: 381-96.

Pritchard, Duncan, Alan Millar, and Adrian Haddock. 2010. The nature and value of knowledge: Three investigations. Oxford: Oxford University Press.

Rödl, Sebastian. 2007. Self-consciousness. Cambridge, MA: Harvard University Press.

Sellars, Wilfrid. 1956. Empiricism and the philosophy of mind. In Minnesota Studies in the Philosophy of Science 1, ed. Herbert Feigl and Michael Scriven, 253-329. Minneapolis: University of Minnesota Press.

Soteriou, Matthew. 2009. The disjunctive theory of perception. Stanford Encyclopedia of Philosophy. http://plato.stanford.edu/entries/perception-disjunctive/

Travis, Charles. 2004. The silence of the senses. Mind 113, no. 449: 59-94.

Williamson, Timothy. 2000. Knowledge and its limits. Oxford: Oxford University Press. 
